\title{
Inhibitory effect of antidepressants on B16F10 melanoma tumor growth
}

\author{
Beata Grygier ${ }^{1}$, Beatriz Arteta ${ }^{2}$, Marta Kubera ${ }^{1}$, Agnieszka Basta-Kaim¹, \\ Bogusława Budziszewska1,3, Monika Leśkiewicz ${ }^{1}$, Katarzyna Curzytek', \\ Weronika Duda 1 , Władysław Lasoń ${ }^{1,4}$, Michael Maes ${ }^{5}$ \\ ${ }^{1}$ Department of Experimental Neuroendocrinology, Institute of Pharmacology, Polish Academy of Sciences, \\ Smętna 12, PL 31-343 Kraków, Poland \\ ${ }^{2}$ Department of Cell Biology and Histology, School of Medicine and Dentistry, Basque Country University, \\ Barrio Sarriena s/n, E 48940 Leioa, Bizkaia, Spain \\ ${ }^{3}$ Department of Biochemical Toxicology, Faculty of Pharmacy, Jagiellonian University, Medical College, \\ Medyczna 9, PL 30-688 Kraków, Poland \\ ${ }^{4}$ Department of Drug Management, Institute of Public Health, Jagiellonian University, Medical College, \\ Grzegórzecka 20, PL 31-351 Kraków, Poland \\ ${ }^{5}$ Maes Clinics @ TRIA, Piyavate Hospital, 998 Rimklongsamsen Road, Bangkok 10310, Thailand
}

Correspondence: Marta Kubera, e-mail: kubera@if-pan.krakow.pl

\begin{abstract}
:
Background: Antidepressant drugs, like fluoxetine, a selective serotonin reuptake inhibitor, desipramine, a nonselective noradrenaline reuptake inhibitor, and mirtazapine, an antagonist of noradrenaline $\alpha_{2}$ auto- and heteroreceptors, are widely used for the treatment of depressive symptoms in cancer patients. Since these antidepressants have different activities targeting the immune system, they might also modulate tumor growth in cancer patients.

Methods: In the present study, we investigated the effects of administration of antidepressant drugs: fluoxetine, desipramine and mirtazapine on B16F10 melanoma tumor growth. These drugs were administered intraperitoneally (ip) for 17 days after subcutaneous injection of B16F10 melanoma cells to male C57BL/6J mice.

Results: Fluoxetine significantly inhibited melanoma solid tumor growth and desipramine tended to decrease this parameter whereas mirtazapine had no effect.

Conclusion: The inhibitory effect of fluoxetine on melanoma growth was associated with an increased mitogen-induced T cell proliferation which may at least partly participate in the mechanism of the antitumor effect of this antidepressant. It appears that the inhibitory effect of fluoxetine on tumor growth is not related with changes in cytokine levels except for IL-10.
\end{abstract}

\section{Key words:}

antidepressants, fluoxetine, desipramine, mirtazapine, B16F10 melanoma, cytokines 


\section{Introduction}

A diagnosis of cancer throws a patient into an extremely stressful and difficult situation. The prevalence of depression among patients with cancer is estimated at from 10 to $71 \%$, and varies by cancer type [25]. Cancer-related depression is associated with faster tumor progression and shortened survival time $[23,34]$. The number of patients with cancer treated with antidepressant drugs has dramatically increased worldwide in the past two decades [9, 29, 30].

Antidepressant drugs, such as tricyclic antidepressant drugs (TCA) and selective serotonin reuptake inhibitors (SSRIs) relieve the symptoms of depression, anxiety and chronic pain in the majority of patients [35, 37]. Moreover, antidepressants alleviate pain, alone or in combination with narcotics, and improve sleep, appetite and energy [21]. They can reduce the severity and frequency of hot flashes in patients treated with chemotherapy, protect non-malignant cells from toxicity of ionizing radiation and chemotherapy, reverse chemotherapy-induced vomiting [22].

On the other hand, some reports have suggested that antidepressants may promote formation and growth of tumors, raising concern about prescribing such medication on a regular basis [37].

The aim of this work was to evaluate the effect of chronic treatment with three antidepressants representing various pharmacological groups: desipramine, fluoxetine or mirtazapine on the neoplastic pathology in mice. With that purpose, we evaluated the effect of repeated administration of antidepressants on $\mathrm{B} 16 \mathrm{~F} 10$ melanoma solid tumor growth. Furthermore, in order to better understand the association between antidepressant effects on tumor pathology and immune system activity, the T-cell proliferative response to concanavalin $\mathrm{A}(\mathrm{Con} \mathrm{A})$, and the production of anti- and pro-tumoral cytokines: interleukin (IL)-1, IL-10, interferon (IFN)- $\gamma$ and vascular endothelial growth factor (VEGF) were also studied.

\section{Materials and Methods}

\section{Animals}

Experiment was performed in the Basque Country University School of Medicine \& Dentistry on sev- enty five 3-5 months old male C57BL/6J mice obtained from Charles River, Barcelona, Spain. Animals were housed up to five per cage, at $22^{\circ} \mathrm{C}$ and $40 \%$ humidity under a $12 \mathrm{~h}$ light-dark cycle, with free access to water and standard food. All tests were approved by the Animal Care and Use Committee at the Basque Country University School of Medicine \& Dentistry, Leioa, Spain, which met the International Guide for the Care and Use of Laboratory Animals.

\section{Cell culture}

B16F10 is a selective variant cell line obtained from pulmonary metastasis syngeneic to $\mathrm{C} 57 \mathrm{BL} / 6 \mathrm{~J}$ mice. Mouse B16F10 melanoma cell line was obtained from ATCC (Manassas, VA, USA). Melanoma cells for subcutaneous $(s c)$ administration were cultured in the Basque Country University School of Medicine \& Dentistry, Leioa, Spain. B16F10 cells grew in monolayers, adherent to the bottom of culture flasks filled with RPMI 1640 supplemented with $10 \%$ fetal calf serum, penicillin $(100 \mathrm{U} / \mathrm{ml})$ and streptomycin $(100 \mu \mathrm{g} / \mathrm{ml})$. The cultures were maintained at $37^{\circ} \mathrm{C}$ in $5 \% \mathrm{CO}_{2}$. Cells in the exponential growth phase were harvested at $80 \%$ confluence, briefly exposed to $0.05 \%$ trypsin solution and pipetted to obtain homogeneous cell suspension. The cell suspension was centrifuged, washed once with phosphate-buffered saline (PBS) and resuspended in PBS at a concentration of $2 \times 10^{6}$ cells per ml. Cell viability was determined by the trypan blue exclusion test. Only single-cell suspensions with $95 \%$ viability were used for inoculation.

\section{Induction of subcutaneous B16F10 melanoma growth}

C57BL/6J males were divided into five groups, five animals per group. Mice were inoculated $s c$ with $3 \times 10^{5}$ B16F10 cells suspended in $0.15 \mathrm{ml}$ of PBS into the left flank region $[7,16]$. Tumor growth was monitored for 18 days. The experiment was repeated three times. Animals for estimation of immunological parameters were sacrificed by decapitation on $18^{\text {th }}$ day after tumor cells inoculation, blood and spleen were collected from each animal. 


\section{Antidepressant drug treatment}

There were two control and three experimental groups. Experimental C57BL/6J mice received daily $i p$ injections of desipramine $(10 \mathrm{mg} / \mathrm{kg}$, Research Biochemicals International, USA), fluoxetine $(10 \mathrm{mg} / \mathrm{kg}$, Lilly Laboratories, USA) or mirtazapine $(20 \mathrm{mg} / \mathrm{kg}$, Organon, The Netherlands) for 17 days. Desipramine and fluoxetine were dissolved in sterile water. Mirtazapine was suspended in $1 \%$ aqueous solution of Tween 80. Control group for desipramine and fluoxetine groups received ip injection of sterile water whereas control group for mirtazapine studies received $1 \%$ aqueous solution of Tween 80 . First drug injection was given $2 \mathrm{~h}$ after injection of tumor cells, last drug injection $-24 \mathrm{~h}$ before sacrificing of animals. Control animals received vehicle throughout the whole experimental period.

\section{Proliferative response of splenocytes to mitogen stimulation in vitro}

Spleens were aseptically dissected out. Immediately after sacrifice, spleens in PBS-EDTA $(1 \% \mathrm{w} / \mathrm{v})$ were minced using a pair of scissors and passed through a fine steel $(70 \mu \mathrm{m}$ diameter) mesh to obtain a homogeneous cell suspension. After centrifugation $(380 \times \mathrm{g}$ at $4^{\circ} \mathrm{C}$ for $10 \mathrm{~min}$ ), the pelleted cells were washed three times in PBS and resuspended in RPMI 1640 complete medium. Splenocytes were cultured for $72 \mathrm{~h}$ at a concentration of $4 \times 10^{6} \mathrm{cells} / \mathrm{ml}$ in the presence or absence of $2.5 \mu \mathrm{g} / \mathrm{ml}$ of Con A. Proliferation was quantified by means of the MTT (3-(4,5-dimethylthiazol-2-yl)-2,5-diphenyltetrazolium bromide; Sigma Aldrich) assay described by us earlier [18] and the absorbance was evaluated after $4 \mathrm{~h}$ in an ELISA reader (Bio-Rad, USA) at $570 \mathrm{~nm}$.

\section{Determination of cytokines}

Blood was centrifuged and plasma was collected and stored at $-70^{\circ} \mathrm{C}$ for analysis of cytokines at a later date. Splenocyte suspensions were seeded at a concentration of $4 \times 10^{6}$ cells $/ \mathrm{ml}$ in 24-well Corning tissue culture plates, and were then stimulated with a mixture of a Con A solution $(2.5 \mu \mathrm{g} / \mathrm{ml})$ and lipopolysaccharide (LPS) solution (from Escherichia coli, serotype O26:B6, Sigma-Aldrich) $(5 \mu \mathrm{g} / \mathrm{ml})$ or remained unstimulated. Cell-free supernatants were collected $48 \mathrm{~h}$ later and stored at $-20^{\circ} \mathrm{C}$. IL- $1 \beta$, IL-10 and IFN- $\gamma$ levels were estimated in plasma and in supernatants whereas VEGF was assayed only in plasma. All the enzyme-linked immunosorbent assays (ELISA) were based on monoclonal-monoclonal antibody pairs and were performed using DuoSet ELISA Development Kits (R\&D Systems, Abingdon, UK).

\section{Statistical analysis}

For a statistical analysis of the results, Statistica 9.0 software (Statsoft, Tulsa, USA), run on a PCcompatible computer, was used. Normality of the distribution of variables and the homogeneity of variances were checked by Shapiro-Wilk's and Levene's tests, respectively. The data were evaluated by a oneway analysis of variance (ANOVA) followed by Dunnett's tests (separately, for desipramine- and fluoxetine-treated animals in comparison to vehicle-treated control mice and for mirtazapine-treated animals in comparison to appropriate control mice). The $\mathrm{p}$ values lower than 0.05 were regarded as statistically significant.

All of the colorimetric assays were conducted in tetraplicates (estimation of cytokines) or sextuples (MTT assay).

\section{Results}

\section{The effect of antidepressant drug administration on B16F10 melanoma solid tumor development}

In order to investigate the effect of antidepressant drugs on melanoma growth in vivo, B16F10 tumor cells were subcutaneously inoculated into syngeneic C57BL/6J mice and during the next 17 days the animals were systematically treated with antidepressants or appropriate vehicle. The wet weight of these tumors was estimated after the animals were sacrificed. Animals treated with desipramine or fluoxetine, but not mirtazapine, displayed reduced tumor growth compared to the appropriate control animals although only for fluoxetine this effect was statistically significant $(\mathrm{F}[2,42]=11.849, \mathrm{p}<0.001)$. A decrease in tumor volume in the group of mice treated with fluoxetine reached $75 \%$ inhibition of overall tumor volume in comparison to the control saline-treated tumor bearing male C57BL/6J mice (Fig. 1). 

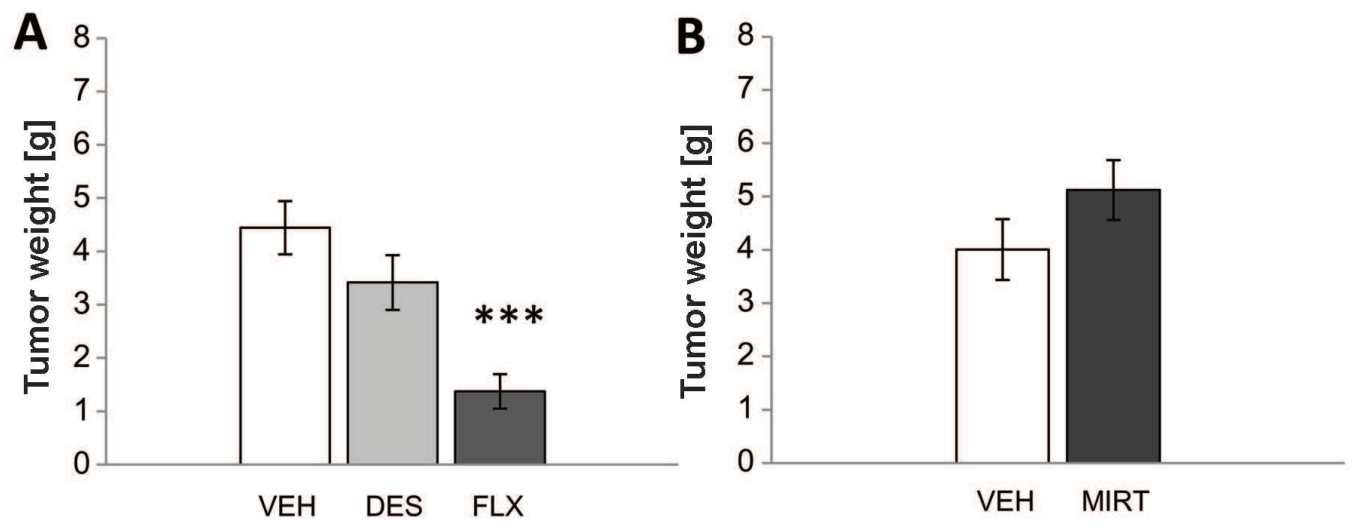

Fig. 1. The effect of antidepressant drugs on B16F10 melanoma growth in vivo. C57BL/6J mice were injected sc with $3 \times 10^{5} \mathrm{~B} 16 \mathrm{~F} 10 \mathrm{cells}$ suspended in $150 \mu$ l of sterile PBS into the left flank region. A series of three experiments ( 5 mice per treatment) was carried out to determine tumor size. Animals were treated ip with a daily dose of desipramine (DES) $(10 \mathrm{mg} / \mathrm{kg}$ ), fluoxetine (FLX) $(10 \mathrm{mg} / \mathrm{kg})$ or mirtazapine (MIRT) (20 mg/kg). After 18 days mice were sacrificed and tumor size was evaluated. Data represent the mean value and SEM. The effects of the different treatments on the tumor weight were compared by an analysis of variance (ANOVA), followed by Dunnett's test, ${ }^{* * *} p<0.001$
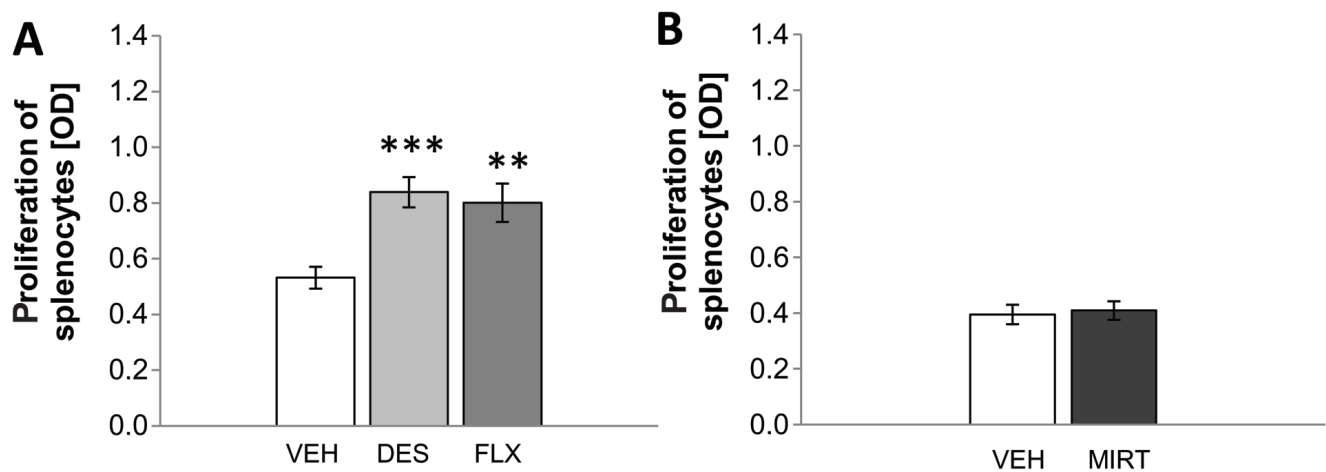

Fig. 2. The effect of antidepressant drugs - desipramine (DES) (10 mg/kg), fluoxetine (FLX) (10 mg/kg) or mirtazapine (MIRT) (20 mg/kg) on proliferation of spleen lymphocytes. Spleen lymphocytes were isolated from antidepressant-treated or untreated B16F10-bearing mice, 18 days after tumor cells injection. After isolation spleen lymphocytes $\left(4 \times 10^{6} \mathrm{cells} / \mathrm{ml}\right)$ were cultured for $72 \mathrm{~h}$ in the presence of Con A. Lymphocyte proliferation was measured by MTT assay. Data represent the mean value and SEM. The effects of the different treatments on proliferation of splenocytes were compared by an analysis of variance (ANOVA), followed by Dunnett's test, ${ }^{* *} p<0.01,{ }^{* * *} p<0.001$

\section{Proliferative activity of splenocytes of tumor-bearing mice}

ANOVA revealed significant effects of desipramine and fluoxetine treatment on proliferative activity of splenocytes from $\mathrm{C} 57 \mathrm{BL} / 6 \mathrm{~J}$ mice bearing solid $\mathrm{B} 16 \mathrm{~F} 10$ tumor $(\mathrm{F}[2,42]=9.11, \mathrm{p}<0.001)$. The proliferative activity of splenocytes estimated by the MTT assay in response to Con A stimulation was significantly higher in C57BL/6J males bearing B16F10 melanoma and treated with desipramine or fluoxetine (by about 52 and $50 \%$, respectively) in comparison with saline treated control mice bearing B16F10 melanoma (Fig. 2A).
ANOVA showed no effect of mirtazapine treatment, on this parameter (Fig. 2B).

\section{Production of cytokines}

ANOVA revealed a significant drug treatment effect on plasma IL-1 $\beta$ level $(\mathrm{F}[2,42]=10.7844$, $\mathrm{p}<$ $0.001)$. Plasma IL-1 $\beta$ was significantly decreased in desipramine- (by 43\%, p $<0.01$ ), but not fluoxetinetreated tumor-bearing animals (Fig. 3A).

ANOVA revealed a significant desipramine and fluoxetine treatment effect on IL-1 $\beta$ production by splenocytes $(\mathrm{F}[2,42]=7.223, \mathrm{p}<0.01)$. The pro- 

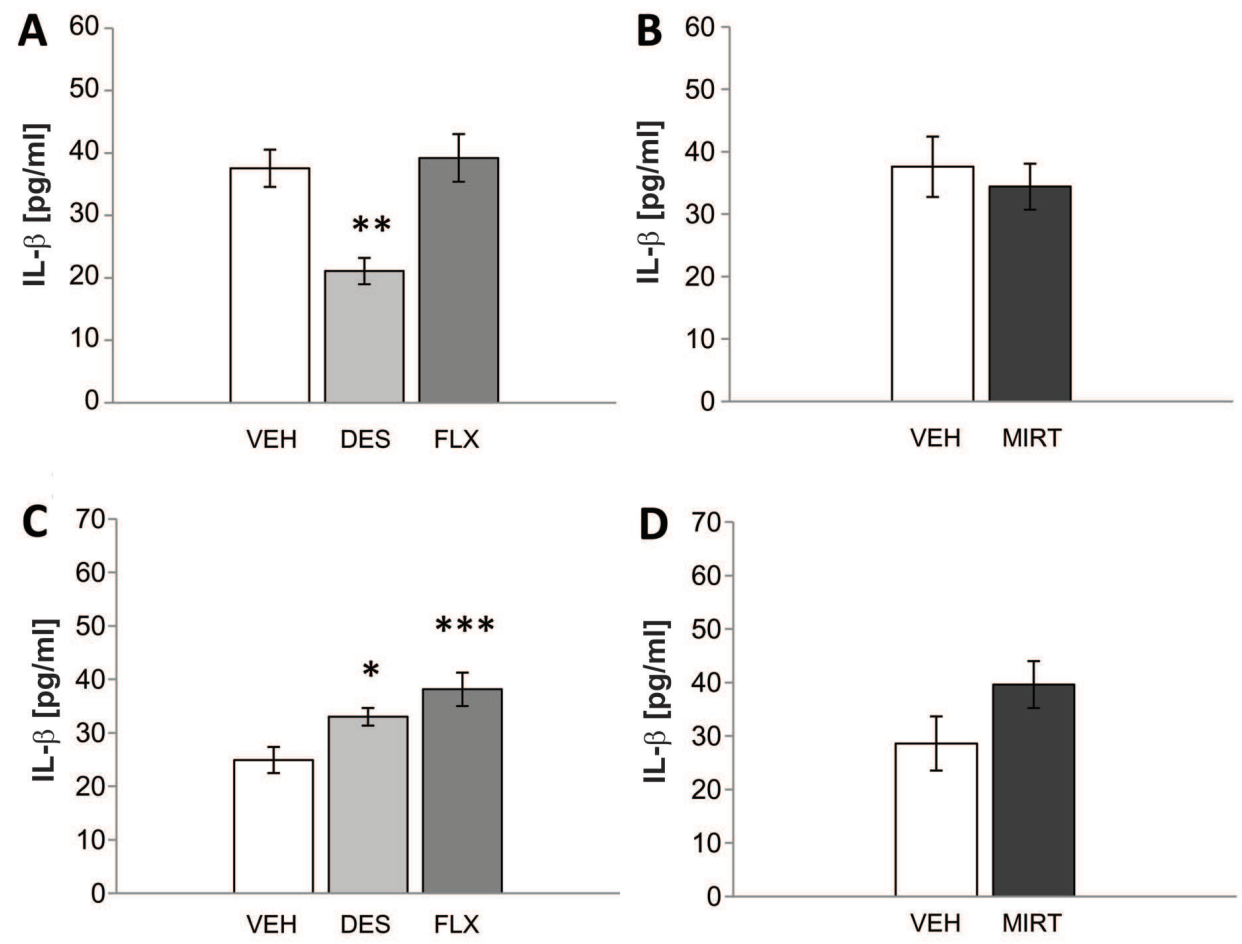

Fig. 3. The effect of antidepressant drugs on IL-1 $\beta$ levels in peripheral blood (A, B) and on IL-1 $\beta$ production by Con A- and LPS-stimulated spleen lymphpocytes (C, D) obtained from B16F10-bearing C57BL/6J mice. Animals were treated ip with a daily dose of desipramine (DES) $(10 \mathrm{mg} / \mathrm{kg})$, fluoxetine (FLX) $(10 \mathrm{mg} / \mathrm{kg}$ ) or mirtazapine (MIRT) $(20 \mathrm{mg} / \mathrm{kg})$. After 18 days mice were sacrificed, blood and splenocytes were collected for cytokine analysis. Data represent the mean value and SEM. The effects of the different treatments on cytokine levels were compared by an analysis of variance (ANOVA), followed by Dunnett's test, ${ }^{*} p<0.05,{ }^{* \star} p<0.01,{ }^{\star * \star} p<0.001$

duction of IL-1 $\beta$ by splenocytes was significantly increased in desipramine- and fluoxetine-treated C57BL/6J mice bearing solid B16F10 tumor by 33 $(\mathrm{p}<0.04)$ and $63 \%(\mathrm{p}<0.001)$, respectively (Fig. $3 \mathrm{C})$.

ANOVA revealed significant effects of desipramine and fluoxetine treatment on plasma ( $\mathrm{F}[2,42]$ $=111.7967 ; \mathrm{p}<0.001)$ and supernatant IL-10 levels $(\mathrm{F}[2,42]=15.7572 ; \mathrm{p}<0.001)$. The reduction of plasma IL-10 was as high as $78 \%$ and $96 \%$ for desipramine and fluoxetine treatment, respectively (Fig. 4A). Splenocytes from desipramine- and fluoxetinetreated animals produced 43 and $68 \%$ less IL-10, respectively (Fig. 4C).

ANOVA revealed significant effects of desipramine and fluoxetine treatment on plasma (F $[2,42]$ $=8.0838 ; \mathrm{p}<0.01)$ and supernatant $(\mathrm{F}[2,42]=$ 8.9502; $\mathrm{p}<0.001)$ IFN- $\gamma$ levels in $\mathrm{C} 57 \mathrm{BL} / 6 \mathrm{~J}$ mice bearing $\mathrm{B} 16 \mathrm{~F} 10$ solid tumor. Plasma IFN- $\gamma$ levels were decreased in desipramine- and fluoxetinetreated mice by 46 and 39\%, respectively (Fig. 5A) whereas IFN- $\gamma$ production by splenocytes was decreased by about $40 \%$ for both drugs in comparison to tumor bearing saline-treated control mice (Fig. 5C).

ANOVA revealed significant drug treatment effects on plasma VEGF level in $\mathrm{C} 57 \mathrm{BL} / 6 \mathrm{~J}$ mice bearing B16F10 solid tumor $(\mathrm{F}[2,42]=13.74, \mathrm{p}<0.001)$. Plasma VEGF level was significantly increased by fluoxetine (by almost 87\%) in C57BL/6J mice bearing solid B16F10 tumor (Fig. 6A).

There was no significant mirtazapine effect on IL-1 $\beta$ IL-10, IFN- $\gamma$ levels both in the spleen and plasma (Figs. 3B, 3D; 4B, 4D; 5B, 5D) and on plasma VEGF levels (Fig. 6B) in C57BL/6J mice bearing solid B16F10 tumor.

\section{Discussion}

The main findings of this study are that: 1) fluoxetine inhibits B16F10 melanoma growth and that this effect 

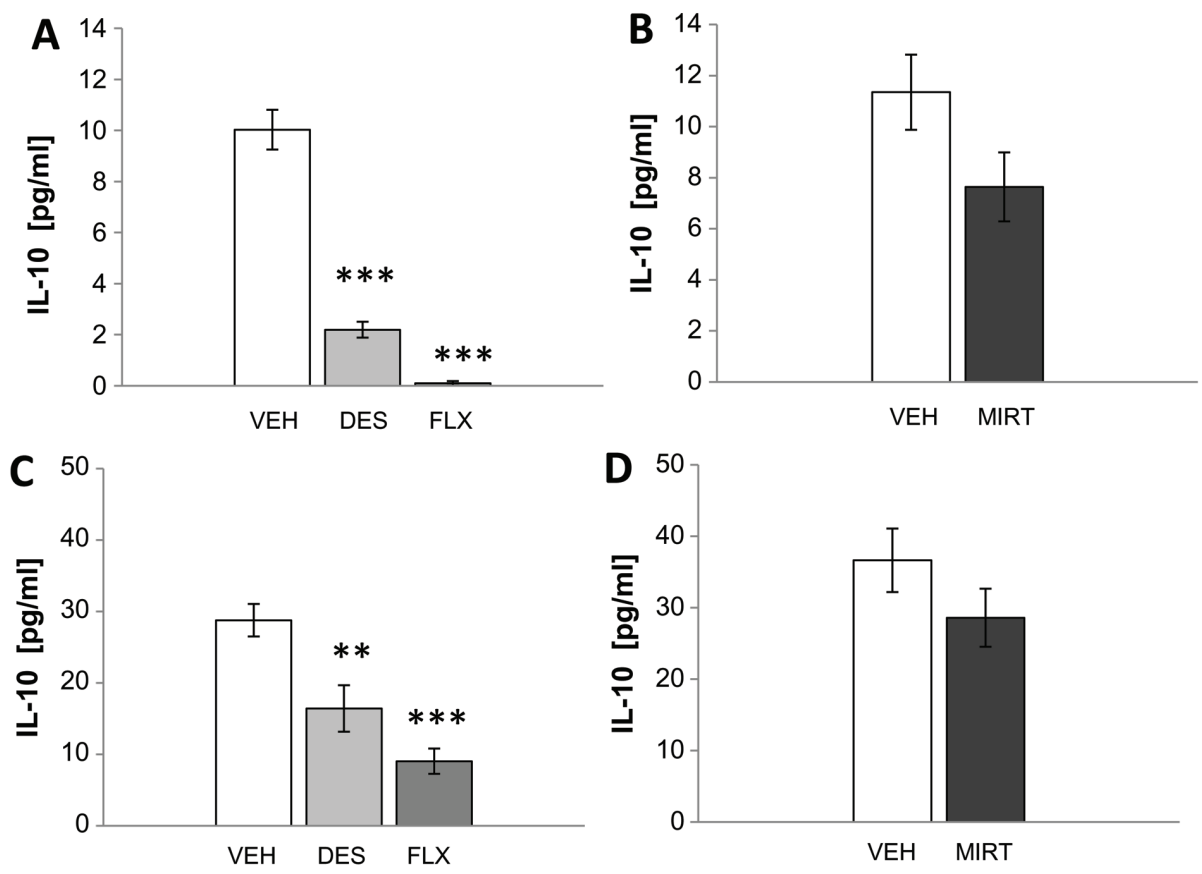

Fig. 4. The effect of antidepressant drugs on IL-10 levels in peripheral blood (A, B) and on IL-10 production by Con A- and LPS-stimulated spleen lymphpocytes (C, D) obtained from B16F10-bearing C57BL/6J mice. Animals were treated ip with a daily dose of desipramine (DES) $(10 \mathrm{mg} / \mathrm{kg})$, fluoxetine (FLX) (10 mg/kg) or mirtazapine (MIRT) $(20 \mathrm{mg} / \mathrm{kg})$. After 18 days mice were sacrificed, blood and splenocytes were colected for cytokine analysis. Data represent the mean value and SEM. The effects of the different treatments on cytokine levels were compared by analysis of variance (ANOVA), followed by Dunnett's test, ${ }^{\star *} p<0.01,{ }^{* * *} p<0.001$
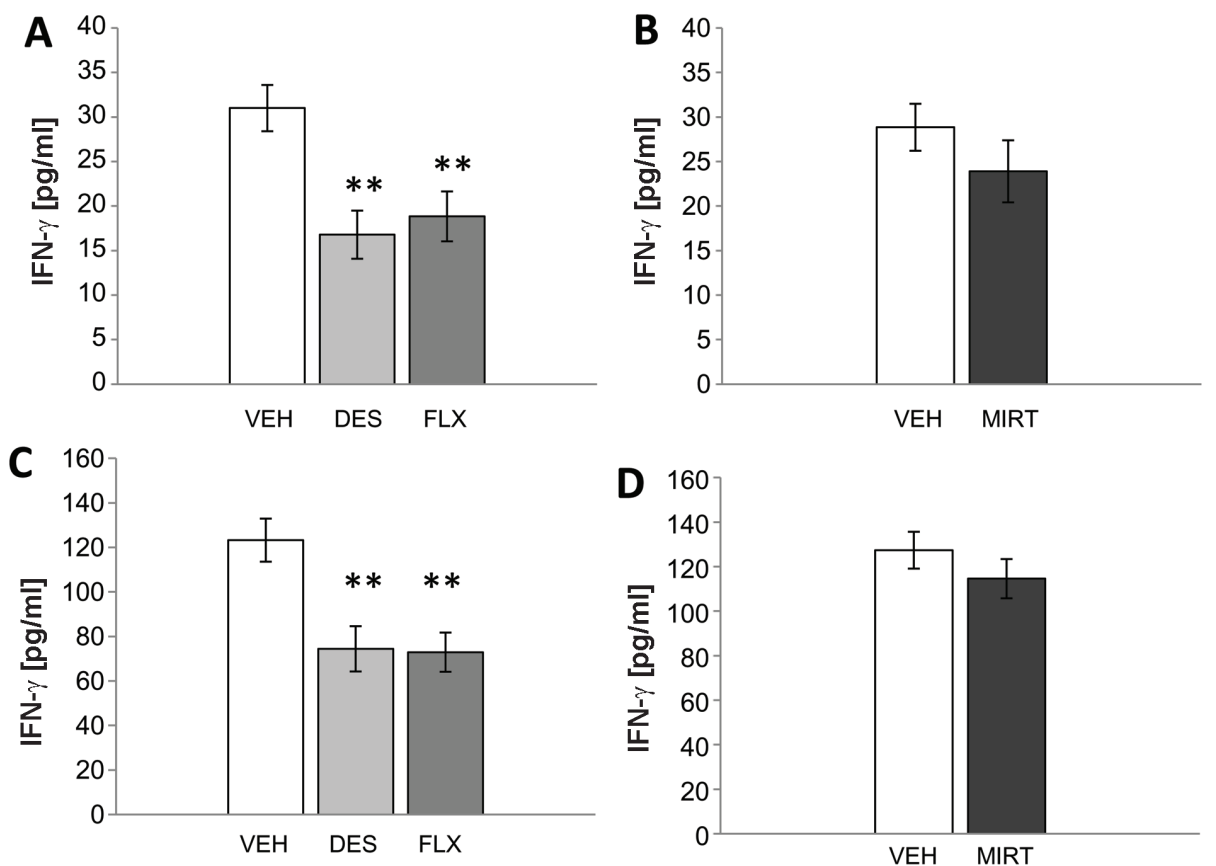

Fig. 5. The effect of antidepressant drugs on IFN- $\gamma$ levels in peripheral blood (A, B) and on IFN- $\gamma$ production by Con A- and LPS-stimulated spleen lymphpocytes (C, D) obtained from B16F10-bearing C57BL/6J mice. Animals were treated ip with a daily dose of desipramine (DES) $(10 \mathrm{mg} / \mathrm{kg})$, fluoxetine (FLX) (10 mg/kg) or mirtazapine (MIRT) $(20 \mathrm{mg} / \mathrm{kg})$. After 18 days mice were sacrificed, blood and splenocytes were collected for cytokine analysis. Data represent the mean value and SEM. The effects of the different treatments on cytokine levels were compared by an analysis of variance (ANOVA), followed by Dunnett's test, ${ }^{* *} p<0.01$ 

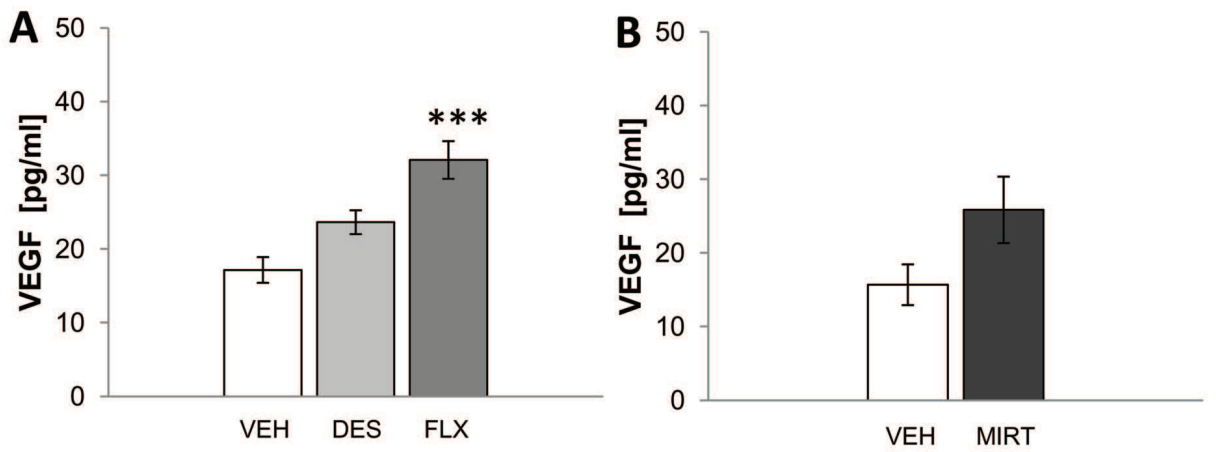

Fig. 6. The effect of antidepressant drugs on VEGF levels in peripheral blood obtained from B16F10-bearing C57BL/6J mice. Animals were treated ip with a daily dose of desipramine (DES) $(10 \mathrm{mg} / \mathrm{kg})(\mathbf{A})$, fluoxetine (FLX) $(10 \mathrm{mg} / \mathrm{kg})(\mathbf{A})$ or mirtazapine (MIRT) (20 mg/kg) (B). After 18 days mice were sacrificed and blood was collected for cytokine analysis. Data represent the mean value and SEM. The effects of the different treatments on VEGF levels were compared by an analysis of variance (ANOVA), followed by Dunnett's test, ${ }^{* * *} \mathrm{p}<0.001$

is accompanied by an increased proliferative activity of splenocytes, inhibition of IL-10 and IFN- $\gamma$ and activation of IL-1 $\beta$ production by splenocytes; 2 ) mirtazapine has no effect on melanoma growth as well as on the immune system activity.

Inhibitory effects of fluoxetine on melanoma growth were also observed in our previous studies on S91 melanoma growth in female DBA/2 mice, although this effect was dependent on the number of tumor cells injected $s c$. Fluoxetine efficiently inhibited tumor growth when $0.3 \times 10^{6} \mathrm{~S} 91$ tumor cells were injected, but had no effect when threefold higher doses of the tumor cells were inoculated [17]. Frick et al. [10] showed that chronic fluoxetine treatment not only inhibited lymphoma growth but also increased latency of appearance of solid tumors and increased survival of mice. Fluoxetine also inhibited jejunal and colonic tumors in rats and xenografts of human colorectal and prostate tumor to athymic nude mice [1, 38]. Moreover administration of fluoxetine for 2 years in the diet did not increase tumorigenesis [3]. Sertraline, another SSRI, inhibited human colorectal carcinoma HT29 xenografts in CD1 nude mice [12].

The dramatic inhibition of solid tumor growth by fluoxetine may be explained by the toxic effects of fluoxetine on melanoma cells and/or by its inhibitory effects on proliferative activity of these cells, and by the stimulatory effects of fluoxetine on cell-mediated immunity. Probably, fluoxetine acts directly on tumor cells to inhibit melanoma progression and has the ability to selectively congest in melanoma cells. Tumor cells in animals undergoing anti-tumor therapy can die by apoptosis and/or necrosis. Apoptosis is a form of cell death in which a programmed sequence of events leads to the ingestion of cell remains by surrounding cells without releasing harmful substances. Necrosis is an accidental cell death without a precise control mechanism, which results in the breakdown of the cell membrane and release of intracellular compounds into the surrounding tissue [27]. Melanoma cells show low levels of spontaneous apoptosis and are relatively resistant to drug-induced apoptosis [32], which is likely to underlie drug-resistance of melanoma. Recently, a selective sensitivity to the cytotoxic effects of fluoxetine was observed in the pheochromocytoma cell line obtained from the rat adrenal gland (rat PC12 cell line). Han and Lee [14] showed that fluoxetine increased the loss of the mitochondrial transmembrane potential, cytochrome c release, caspase-3 activation, formation of reactive oxygen species, induced over-expression of Bax, reduced Bcl-2 level in PC12 cell line, whereas amitriptyline and tranylcypromine induced opposite effects. However, pro-apoptotic effect of another tricyclic antidepressant chloropramine (Anafranil) specially in combination with imatinib mesylate (Gleevec) was found in the rat C6 glioma [4]. Arimochi and Morita [2] reported that fluoxetine revealed cytotoxic actions in human HT29 colon carcinoma cells. Fluoxetine was able to induce apoptosis in rat glioblastoma and human neuroblastoma cells $[20,33]$. B16F10 melanoma cells are probably particularly sensitive to proapoptotic and pro-necrotic effect of fluoxetine although this suggestion needs verification in in vitro studies and we have already undertaken these studies.

Antidepressant drugs may also inhibit proliferative activity of tumor cells. In the present study, we showed that fluoxetine inhibited proliferation of 
B16F10. Fluoxetine inhibited serotonin reuptake by tumor cells thereby increasing serotonin level in tumor cell environment but decreasing serotonin level inside tumor cells and it was shown that such manipulation with serotonin level decreased proliferative activity of tumor cells. The serotonin reuptake inhibitors fluoxetine and zimeldine inhibited the proliferation of human prostate carcinoma cells in vitro in a concentration-dependent manner. This effect was attributed to the inhibition of serotonin uptake by prostate cells, for which serotonin is mitogenic [1]. Krishnan et al. [15] showed for human cervical and breast cancer cells that fluoxetine mediated G0/G1 arrest by inducing a functional inhibition of cycline-dependent kinase subunit. A previous study has shown that SSRIs might interfere with DNA synthesis in Burkitt lymphoma cells. The SSRI-induced inhibition of S-phase entry correlated with relative accumulation of cells in G0/G1 phase of cell cycle [31]. When compared to cytotoxic agents e.g., doxorubicin, vincristine and 5-fluorouracil, the SSRIs (paroxetine, sertraline) showed comparable activity in human colorectal carcinoma cell line HT29 or a superior effect in multidrug resistant LS1034 cell line [12]. It was shown that SSRIs-treated cells exhibited a significant decrease in the $C d c 6$ gene expression. Cdc6 gene function is required for the initiation of DNA replication and is a key regulatory protein during cell cycle progression [24]. Fluoxetine inhibited proliferation of lung (A549), colon (HT29), neuroblastoma (SKNAS), medulloblastoma/rhabdomyosarcoma (TE671), astrocytoma (MOGGCCM) and breast (T47D) cancer cells in a dose-dependent manner. Fluoxetine inhibited phosphorylation of ERK1/2 kinases in a time- and concentration-dependent manner, followed by reduced phosphorylation of transcription factor c-Myc in A549 and HT29 cells. After treatment with fluoxetine, A549 and HT29 cells demonstrated a concentration-dependent decrease in the expression of $c$-fos, $c$ jun, cyclin $A$, cyclin $D 1$ and an increased expression of $p 21^{\text {wafl }}$ and $p 53$ genes, which resulted in slowing of the cell cycle [36].

Recently, it has been shown that, among SSRIs, only fluoxetine can elevate the extracellular norepinephrine and dopamine levels in the prefronatal cortex, suggesting that fluoxetine is not completely selective for the serotonin reuptake system [6] and interacts with the norepinephrine reupatke system in the brain, as well. Therefore, it seems likely that fluoxetine causes the antiprolioferative action on tumor cells interacting with a target associated with the action of not only serotonin but also norepinephrine or dopamine.

We may speculate that the inhibition of tumor growth by drugs administrated after tumor cell injection is connected with drug-induced neurogenesis in solid tumors. Tumors are able to release neurotrophic factors, as already observed in some human cancers, although such studies have not been performed for melanomas [26]. Antidepressant drugs via stimulation of production of this neurotrophic factors, may increase neurogenesis in solid tumors. These nerve cells can release neurotransmitters to which tumor cells are susceptible and which modulate tumor cell proliferation. It was shown that chronic desipramine administration to experimental animals significantly elevated the serum norepinephrine concentration whereas norepinephrine may modulate tumor growth.

The inhibition of tumor growth in animals treated with fluoxetine after tumor cell injection is probably the result of not only a direct toxic effect on melanoma cells but also an indirect effect via stimulation of anti-cancer immune-response. In the present study, it was shown that fluoxetine increased Con A-induced T-cell proliferation. Similar stimulatory effects were observed by Frick et al. [10], but that study was performed on animals without tumor cells after oral administration of fluoxetine for four weeks. In our former studies, we also observed the increase in proliferative activity of splenocytes in response to Con A after two and four weeks of desipramine and one or two weeks of fluoxetine ip administration to C57BL/ $6 \mathrm{~J}$ mice $[18,19]$.

In the present studies, no changes in plasma level of IL-1 $\beta$ and a significant increase in mitogen-induced ability of splenocytes to produce this cytokine was observed in fluoxetine-treated subcutaneous B16F10 melanoma-bearing animals. Other studies suggest an involvement of IL- $1 \alpha$ in the progression of this experimental tumor although the lack of a direct antiproliferative activity in vitro against B16F10 cells was also shown [5]. Treatment of subcutaneous tumor-bearing mice with intraperitoneal IL- $1 \alpha$ administration resulted in a dose-dependent inhibition of tumor growth with the greatest activity obtained with the maximum tolerated dose of IL-1 $\alpha$ [5]. On the other hand, IL-1 $\alpha$ did not modify the number of metastases after intravenous injection of B16F10 melanoma cells $[5,8]$.

The increase in IL-1 $\beta$ level is connected with an increased activity of interleukin-1 converting enzyme. On the other hand, IL-18, a cytokine with strong antitumor 
activity in experimental models requires processing by interleukin-1 converting enzyme for expressing its activity [28], so we may speculate that also an increase in not estimated by us IL-18 takes place in fluoxetine-treated tumor bearing $\mathrm{C} 57 \mathrm{BL} / 6 \mathrm{~J}$ mice.

In the present paper, an increase in IL- $1 \beta$ production was observed only in animals treated with antidepressants after tumor cell inoculation, whereas the production of IFN- $\gamma$ and IL-10, cytokines typical of Th1 and $\mathrm{Th} 2$, respectively, was decreased. The increase in IL-1 $\beta$ production indicates the activation of macrophages. The increase in IL-1 $\beta$ level, via stimulation of IL-2 production in $\mathrm{T}$ cells, may also be responsible for the increase in proliferative activity of these cells.

The level of IL-10 plays an important role in modulation of melanoma tumor progress. Among others it was shown that IL-10 may directly promote B16-melanoma growth by induction of tumor and vascular cell proliferation [11]. The inhibition of solid tumor growth observed in the present study may be connected with an decreased ability of splenocytes to produce IL-10.

On the other hand, an optimal concentration of IFN- $\gamma$ and IL-10 is needed for proper anti-tumor response. In the present paper, IFN- $\gamma$ and IL-10 production were strongly inhibited 18 days after sc melanoma cell injection and $24 \mathrm{~h}$ after the last antidepressant drug application. Although the levels of cytokines were examined only at one time point, we may speculate that during solid melanoma tumor growth the level of cytokines were optimal for stimulation of anti-tumor response and inhibition of the tumor growth.

In the present studies, chronic fluoxetine administration significantly increased plasma VEGF level in tumor-bearing mice. VEGF is a potent mitogen and survival factor for endothelial cells and an important factor promoting angiogenesis and development of metastasis also in experimental melanoma [40]. On the other hand, recent studies have shown that VEGF is also an essential mediator of the neurogenic and behavioral action of antidepressants [39], whereas inhibition of VEGF action blocks the antidepressant effects of fluoxetine on sucrose preference, immobility in the forced swim test, and latency to feed in the novelty suppressed feeding paradigm [13]. We may speculate that although fluoxetine increased peripheral level of VEGF, it might inhibit local, tumor celldependent VEGF production or expression of VEGF receptor sub-types on melanoma cells, but this sug- gestion needs further studies. Moreover, fluoxetine, via increasing blood VEGF level, increased concentration of antidepressant drugs in tumor microenvironment and enhances drug-induced cytotoxicity against melanoma cells. The present study showed that although fluoxetine significantly increased serum VEGF level, it also inhibited primary tumor growth.

\section{Acknowledgment:}

This study was supported by a research grant N 401097 32/2074 from the Ministry of Sciences and High Education, Warszawa, Poland.

\section{References:}

1. Abdul M, Logothetis CJ, Hoosein NM: Growth-inhibitory effects of serotonin uptake inhibitors on human prostate carcinoma cell lines. J Urol, 1995, 154, 247-250.

2. Arimochi H, Morita K: Characterization of cytotoxic actions of tricyclic antidepressants on human HT29 colon carcinoma cells. Eur J Pharmacol, 2006, 541, 17-23.

3. Bendele RA, Adams ER, Hoffman WP, Gries CL, Morton DM: Carcinogenicity studies of fluoxetine hydrochloride in rats and mice. Cancer Res, 1992, 52, 6931-6935.

4. Bilir A, Erguven M, Oktem G, Ozdemir A, Uslu A, Aktas E, Bonavida B: Potentiation of cytotoxicity by combination of imatinib and chlorimipramine in glioma. Int J Oncol, 2008, 32, 829-839.

5. Brunda MJ, Wright RB, Luistro L, Harbison ML, Anderson TD, McIntyre KW: Enhanced antitumor efficacy in mice by combination treatment with interleukin-1 alpha and interferon-alpha. J Immunother Emphasis Tumor Immunol, 1994, 15, 233-241.

6. Bymaster FP, Zhang W, Carter PA, Shaw J, Chernet E, Phebus L, Wong DT, Perry KW: Fluoxetine, but not other selective serotonin uptake inhibitors, increases norepinephrine and dopamine extracellular levels in prefrontal cortex. Psychopharmacology (Berl), 2002, 160, 353-361.

7. Chlebda E, Merwid-Ląd A, Szumny D, Trocha M, Fereniec-Gołębiewska L, Gębarowska E, Kowalski P, Szelag A: Antitumor effect of macrolides - erythromycin and roxithromycin in B16 melanoma-transplanted mice. Pharmacol Rep, 2007, 59, 269-274.

8. De Galdeano AG, Boyano D, Cañavate L: Effect induced by interleukin-1 on the behaviour of B16F10 melanoma cells. Oncol Rep, 1999, 6, 225-228.

9. Fisch M: Treatment of depression in cancer. J Natl Cancer Inst Monogr, 2004, 32, 105-111.

10. Frick LR, Palumbo ML, Zappia MP, Brocco MA, Cremaschi GA, Genaro AM: Inhibitory effect of fluoxetine on lymphoma growth through the modulation of antitumor T-cell response by serotonin-dependent and independent mechanisms. Biochem Pharmacol, 2008, 75, 1817-1826. 
11. García-Hernández ML, Hernández-Pando R, Gariglio P, Berumen J: Interleukin-10 promotes B16-melanoma growth by inhibition of macrophage functions and induction of tumour and vascular cell proliferation. Immunology, 2002, 105, 231-243.

12. Gil-Ad I, Zolokov A, Lomnitski L, Taler M, Bar M, Luria D, Ram E, Weizman A: Evaluation of the potential anti-cancer activity of the antidepressant sertraline in human colon cancer cell lines and in colorectal cancerxenografted mice. Int J Oncol, 2008, 33, 277-286.

13. Greene J, Banasr M, Lee B, Warner-Schmidt J, Duman RS: Vascular endothelial growth factor signaling is required for the behavioral actions of antidepressant treatment: pharmacological and cellular characterization. Neuropsychopharmacology, 2009, 34, 2459-2468.

14. Han YS, Lee CS: Antidepressants reveal differential effect against 1-methyl-4-phenylpyridinium toxicity in differentiated PC12 cells. Eur J Pharmacol, 2009, 604, 36-44.

15. Krishnan A, Hariharan R, Nair SA, Pillai MR: Fluoxetine mediates $\mathrm{G} 0 / \mathrm{G} 1$ arrest by inducing functional inhibition of cyclin dependent kinase subunit (CKS)1. Biochem Pharmacol, 2008, 75, 1924-1934.

16. Kubera M, Grygier B, Arteta B, Urbańska K, BastaKaim A, Budziszewska B, Leśkiewicz M et al.: Agedependent stimulatory effect of desipramine and fluoxetine pretreatment on metastasis formation by B $16 \mathrm{~F} 10$ melanoma in male C57BL/6 mice. Pharmacol Rep, 2009, 61, 1113-1126.

17. Kubera M, Grygier B, Urbańska K, Arteta B, Leśkiewicz M, Basta-Kaim A, Budziszewska B et al.: Inhibitory effect of fluoxetine on S91 melanoma growth in DBA mice. Cent Eur J Immun, 2008, 33, Suppl 1, 40.

18. Kubera M, Holan V, Mathison R, Maes M: The effect of repeated amitriptyline and desipramine administration on cytokine release in C57BL/6 mice. Psychoneuroendocrinology, 2000, 25, 785-797.

19. Kubera M, Simbirtsev A, Mathison R, Maes M: Effects of repeated fluoxetine and citalopram administration on cytokine release in C57BL/6 mice. Psychiatry Res, 2000, 96, 255-266.

20. Levkovitz Y, Gil-Ad I, Zeldich E, Dayag M, Weizman A: Differential induction of apoptosis by antidepressants in glioma and neuroblastoma cell lines: evidence for p-c-Jun, cytochrome c, and caspase-3 involvement. J Mol Neurosci, 2005, 27, 29-42.

21. Lieb J: Antidepressants, eicosanoids and the prevention and treatment of cancer. A review. Prostaglandins Leukot Essent Fatty Acids, 2001, 65, 233-239.

22. Lieb J: Antidepressants, prostaglandins and the prevention and treatment of cancer. A review. Med Hypotheses, 2007, 69, 684-689.

23. Lloyd-Williams M, Shiels C, Taylor F, Dennis M: Depression-an independent predictor of early death in patients with advanced cancer. J Affect Disord, 2009, 113, 127-132.

24. Luo F, Yee JK, Huang SH, Wu LT, Jong AY: Downregulation of human $\mathrm{Cdc} 6$ protein using a lentivirus RNA interference expression vector. Methods Mol Biol, 2006, 342, 287-293.
25. Massie MJ: Prevalence of depression in patients with cancer. J Natl Cancer Inst Monogr, 2004, 32, 57-71.

26. Miknyoczki SJ, Lang D, Huang L, Klein-Szanto AJ, Dionne CA, Ruggeri BA: Neurotrophins and Trk receptors in human pancreatic ductal adenocarcinoma: expression patterns and effects on in vitro invasive behavior. Int J Cancer, 1999, 81, 417-427.

27. Milijkovic D, Markovic M, Bogdanovic N, Mostarica Stojkovic M, Trajkovic D: Necrotic tumor cells oppositely affect nitric oxide production in tumor cell lines and macrophages. Cell Immunol, 2002, 215, 72-77.

28. Nagai H, Hara I, Horikawa T, Oka M, Kamidono S, Ichihashi M: Gene transfer of secreted-type modified interleukin-18 gene to B16F10 melanoma cells suppresses in vivo tumor growth through inhibition of tumor vessel formation. J Invest Dermatol, 2002, 119, 541-548.

29. Ng CG, Boks MP, Zainal NZ, de Wit NJ: The prevalence and pharmacotherapy of depression in cancer patients. J Affect Disord, 2011, 131, 1-7.

30. Rodin G, Katz M, Lloyd N, Green E, Mackay JA, Wong RK: Treatment of depression in cancer patients. Curr Oncol, 2007, 14, 180-188.

31. Serafeim A, Holder MJ, Grafton G, Chamba A, Drayson MT, Luong QT, Bunce CM et al.: Selective serotonin reuptake inhibitors directly signal for apoptosis in biopsy-like Burkitt lymphoma cells. Blood, 2003, 101, 3212-3219.

32. Soengas MS, Lowe SW: Apoptosis and melanoma chemoresistance. Oncogene, 2003, 22, 3138-3151.

33. Spanová A, Kovárů H, Lisá V, Lukásová E, Rittich B: Estimation of apoptosis in C6 glioma cells treated with antidepressants. Physiol Res, 1997, 46, 161-164.

34. Spiegel D: Mind matters in cancer survival. Psychooncology, 2012, 21, 588-593.

35. Steingart AB, Cotterchio M: Do antidepressants cause, promote, or inhibit cancers? A review. J Clin Epidemiol, 1995, 48, 1407-1412.

36. Stepulak A, Rzeski W, Sifringer M, Brocke K, Gratopp A, Kupisz K, Turski L, Ikonomidou C: Fluoxetine inhibits the extracellular signal regulated kinase pathway and suppresses growth of cancer cells. Cancer Biol Ther, 2008, 7, 1685-1693.

37. Sternbach H: Are antidepressants carcinogenic? A review of preclinical and clinical studies. J Clin Psychiatry, 2003, 64, 1153-1162.

38. Tutton PJ, Barkla DH: Effect of an inhibitor of noradrenaline uptake, desipramine, on cell proliferation in the intestinal crypt epithelium. Virchows Arch B Cell Pathol Incl Mol Pathol, 1989, 57, 349-352.

39. Warner-Schmidt JL, Duman RS. VEGF is an essential mediator of the neurogenic and behavioral actions of antidepressants. Proc Natl Acad Sci USA, 2007, 104, 4647-4652.

40. Zhang W, Lu Y, Xu B, Wu J, Zhang L, Gao M, Zheng S et al.: Acidic mucopolysaccharide from holothuria leucospilota has antitumor effect by inhibiting angiogenesis and tumor cell invasion in vivo and in vitro. Cancer Biol Ther, 2009, 8, 1489-1499.

Received: February 13, 2012; in the revised form: November 5, 2012; accepted: December 11, 2012 